\title{
Development and validation of stability indicating HPLC method for the simultaneous analysis of amlodipine, hydrochlorothiazide and valsartan in pharmaceutical formulation
}

\begin{abstract}
A simple, specific, accurate and precise, stability indicating HPLC method for the simultaneous determination of antihypertensive drug combination consisting of amlodipine (AML), hydrochlorothiazide (HCT) and valsartan (VAL) was developed and validated. The optimized conditions for the separation of the three analytes was consisted of ODS C-18 $(250 \mathrm{~mm} \times 4.6 \mathrm{~mm}$ i.d. $5 \mu \mathrm{m})$ column, mobile phase: acetonitrile-potassium dihydrogen phosphate $\mathrm{pH} 3.5$ - acetonitrile $(45: 55 \% \mathrm{v} / \mathrm{v})$. Column temperature was maintained at $40 \mathrm{oC}$; mobile phase flow rate: $1.5 \mathrm{~mL} / \mathrm{min}$; wave length : $230 \mathrm{~nm}$; and injection of $20 \mu \mathrm{L}$. The precision of the method was measured through adequate repeatability or intraday precision $(\mathrm{RSD} \leq 2)$ and interday precision $(\mathrm{RSD} \leq 2)$. The method demonstrated adequate linearity of detector response over the range of $0.5-250 \%$. The limits of detection for AML, HCT and VAL were $0.011,0.010$ and $0.010 \mu \mathrm{g} / \mathrm{mL}$, while the limits of quantification were $0.032,0.020$ and $0.019 \mu \mathrm{g} / \mathrm{mL}$ respectively. The method also showed adequate robustness to variations in mobile phase, $\mathrm{pH}$, and column temperature and acetonitrile concentrations. The full recoveries of each working standard for all compounds were within ICH specifications of $98-101 \%$ which showed that the method was accurate. The proposed method proved to be stability indicating by resolution of the analytes from their accelerated storage conditions products. The developed method is rapid (run time $8 \mathrm{~min}$ ), selective, requires simple sample preparation procedures and simple mobile phase combinations. It is also cost effective and represents a good procedure for determination of AML, HCT and VAL in bulk raw materials and pharmaceutical dosage forms.
\end{abstract}

Keywords: column temperature, sample preparation, blood pressure, hypertension, acetonitrile
Volume 6 Issue 5 - 2017

\author{
Abdalla Ahmed Elbashir, Rami Ali Mohammed \\ Osman \\ Department of Chemistry, University of Khartoum, Sudan
}

Correspondence: Abdalla Ahmed Elbashir, Department of Chemistry, Faculty of science, University of Khartoum, Sudan, Email aaelbashir@uofk.edu

Received: August 01, 2017 | Published: December 21, 2017
Abbreviations: AML, amlodipine; $\mathrm{HCT}$, hydrochlorothiazide; VAL, valsartan; FDA, food and drug administration; USP, U.S. pharmacopia; ICH, international conference on harmonization; LOD, limit of detection; LOQ, limit of quantification

\section{Introduction}

Hypertension or high blood pressure, sometimes called arterial hypertension, is a chronic medical condition in which the blood pressure in the arteries is elevated. This requires the heart to work harder than normal to circulate blood through the blood vessels. The main factor that characterizes a rational drug combination is a synergistic action without side effects. In 2009, the US Food and Drug Administration (FDA) and the European Medicines Agency approved a triple fixed-dose combination of AML, HCT and VAL. It was found that the use of this triple combination was generally more effective in reducing blood pressure and providing overall blood pressure control than the dual combination therapies regardless of age, race, gender, ethnicity, or hypertension severity. ${ }^{1,2}$

Amlodipine besylate (AML) is chemically described as 3-Ethyl-5- methyl ( \pm )-2-(2-aminoethoxy) methyl-4-(2chlorophenyl)-1, 4-dihydro-6-methyl-3, 5- pyridinedicarboxylate, monobenzenesulphonate (Figure 1A). AML tablets are formulated as white tablets equivalent to $2.5,5$, and $10 \mathrm{mg}$ of AML for oral administration. AML is formulated as the besylate salt of AML, a long-acting calcium channel blocker. ${ }^{3}$
Hydrochlorothiazide (HCT) is a white, practically odorless crystalline powder, slightly soluble in water, sparingly soluble in alcohol and soluble in acetone (pKa 7.0). HCT is chemically described as 6-chloro-1,1-dioxo-3, 4-dihydro-2H-1, 2, 4-benzothiadiazine-7sulfonamide (Figure 1B). ${ }^{4-6}$

Valsartan (VAL) is a white fine powder. It is soluble in ethanol and methanol but slightly soluble in water. Its melting point is $117 \mathrm{oC}$. VAL is available as tablets for oral administration, containing 40,80 , 160 or $320 \mathrm{mg}$ of the drug. VAL is a nonpeptide, orally active and specific angiotensin II receptor blocker acting on the AT1 receptor subtype. VAL is chemically described as $\mathrm{N}-(1$-oxopentyl)-N-[2'-(1Htetrazol-5-yl) [1, 1'-0biphenyl-4-yl] methyl]-L-valine (Figure 1C).

Literature survey revealed that a number of methods have been reported for estimation of AML, HCT and VAL individually or in combination with other drugs. However, there is very few analytical methods reported for the simultaneous analysis of these drugs in a combined dosage formulation. The reported methods are UV spectrophotometric, ${ }^{7-12}$ spectrofluorimetric ${ }^{13}$ HPLC and HPTLC, ${ }^{14-25}$ capillary electrophoresis ${ }^{26-29}$ and electrochemical ${ }^{30-32}$ methods.

Stability testing is an important issue in the process of drug product development. The purpose of stability testing is to provide evidence on how the quality of a drug substance or drug product varies with time under the influence of a variety of environmental factors, such as temperature, humidity, and light, and enables recommendation of 
storage conditions, retest periods, and shelf lives to be established. The two main aspects of a drug product that play an important role in shelf life determination are assay of the active drug and degradation products generated during the stability study. The drug product in a stability test sample needs to be determined using a stability indicating method, as recommended by the International Conference on Harmonization (ICH) guidelines ${ }^{33}$ and U.S. Pharmacopia (USP) ${ }^{34}$ Although stability indicating methods have been reported for assay of various drugs in drug products, most of them describe assay procedures for drug products containing only one active drug substance. To best of our knowledge no HPLC stability indicating method for the simultaneous determination of AML, HCT and VAL was reported. Therefore the aim of this work is to develop stability indicating HPLC method for the simultaneous determination of AML, HCT and VAL in mixtures without the need of prior separation step.<smiles>CS(=O)(=O)c1cc2c(cc1Cl)NCNS2(=O)=O</smiles>

IA: HCT.<smiles>CCOC(O)c1c(COCCN)ncc(C(=O)OC)c1-c1ccccc1Cl</smiles>

IB: AML.<smiles>CCCCC(=O)N(Cc1ccc(-c2ccccc2-c2nnn[nH]2)cc1)[C@@H](CC(=O)O)C(C)C</smiles>

IC:VAL

Figure I Chemical structures of amlodipine (AML), hydrochlorothiazide (HCT) and valsartan (VAL).

\section{Experimental}

\section{Materials}

AML, HCT and VAL working standards were obtained from Azal pharmaceutical industries company Ltd, (Khartoum, Sudan). Acetonitrile HPLC grade, Methanol HPLC grade, potassium dihydrogen orthophosphate AR was purchased from Scharlau chemical (Spain). High purity deionised water was obtained from Azal pharmaceutical (Khartoum, Sudan) purification system.

\section{Methods}

\section{Instrumentation}

Chromatographic separation was performed with Shimadzu high performance liquid chromatography having C18, ODS $(250 \mathrm{~mm} \times 4.6 \mathrm{~mm}), 5.0 \mu \mathrm{m}$ analytical column with photodiode array detector provided by Auto sampler and the Chromatographic data were recorded by LC Solution software. Absorbance was carried out by using UV-visible spectrophotometer model Shimadzu 1800 with quartz cells of $1 \mathrm{~cm}$ optical path length, $\mathrm{pH}$ meter was used for $\mathrm{pH}$ measurements, analytical balance and ultrasonic bath.

\section{Chromatographic conditions}

For HPLC a number of preliminary trials were conducted with combinations of different organic solvents, compositions, and flow rate to check the retention time, shape, resolution, and other chromatographic parameters. Among all tried experiments, the mobile phase combination is potassium dihydrogen orthophosphate AR $(0.05 \mathrm{M})$ in water:acetonitrile $(45: 55 \% \mathrm{v} / \mathrm{v})$ adjust to $\mathrm{pH} 3.5$. The solution was degassed in an ultrasonic water bath for 5minutes and filtered through $0.45 \mu \mathrm{m}$ nylon filter. The instrumental settings flow rate of $1.5 \mathrm{~mL} / \mathrm{min}$; the column temperature is $40^{\circ} \mathrm{C}$, and detector wavelength is $230 \mathrm{~nm}$ found to be most suitable.

\section{Preparation of standard and sample solutions}

Stock standard solutions of AML, HCT and VAL (200, 200 and 250 $\mu \mathrm{g} / \mathrm{mL}$ ) respectively: An accurately 20,20 and 25mg of AML, HCT and VAL standards were dissolved in mobile phase, transferred into $100 \mathrm{~mL}$ volumetric flask, diluted with same solvent and mixed well.

Standard solutions of AML, HCT and VAL (40, 40 and 50 $\mathrm{\mu g}$ / $\mathbf{m L}$ ): The standard solutions were prepared by dilution of the stock standard solution with mobile phase to reach a concentration range $0.20-80 \mu \mathrm{g} / \mathrm{mL}$ for AML, $0.2-80 \mu \mathrm{g} / \mathrm{mL}$ for HCT and $0.25-100 \mu \mathrm{g} / \mathrm{mL}$ for VAL. Triplicate $20 \mu \mathrm{L}$ injections were made for each concentration and chromatographed under the condition described above. The peak area of each concentration was plotted against the corresponding concentration to obtain the calibration graph and regression equation was computed.

\section{Assay of commercial tablets}

Ten Exforge HCT tablets were weighed and their mean was determined. After grinding the tablets into a fine powder in glass mortar, an accurately weighed quantity of the tablet powder equivalent $5 \mathrm{mg}$ AML, $12.5 \mathrm{mg}$ HCT and $160 \mathrm{mg}$ VAL the solution was stirred for $10 \mathrm{~min}$ then diluted with mobile phase into a $100-\mathrm{mL}$ volumetric flask. The sample solution was then filtered using $0.45 \mu \mathrm{m}$ filters (Millipore, Milford, MA).

\section{Stability study}

The samples were kept in the stability chamber (Thermaolab) set at accelerated storage conditions ${ }^{38}$ of $40 \pm 2^{\circ} \mathrm{C}$ and $75 \pm 5 \%$ relative humidity and in real storage conditions of $25 \pm 2{ }^{\circ} \mathrm{C}$ and $60 \%$ relative humidity. The samples were periodically monitored by the HPLC analysis. Analyses were carried out at time 0 and after storage of 1,2, and 3 months in the stability chamber.

\section{Results}

\section{Chromatography optimization}

The chromatographic conditions were optimized to achieve the best resolution and peak shape for AML, HCT, and VAL. Different 
mobile phases containing acetonitrile in phosphate buffer were examined. With acetonitrile content $45 \%$ or less, the retention time for VAL was far (retention time $>10 \mathrm{~min}$ ) and the resolution between the AML and HCT less than 2.5, with decreasing of acetonitrile more than $40 \%$ the retention time of VAL too far up to $15 \mathrm{~min}$ eluted. On the other hand to give short time increased the acetonitrile to $60 \%$, the retention time for valsartan was short (retention time $<5.5 \mathrm{~min}$ ) but the resolution between the AML and HCT less than 2.0, moreover phosphate buffers of $\mathrm{pH}$ 3.0-7.0 were tried but the peak shapes for the drugs were sufficiently symmetrical only for $\mathrm{pH}$ value below 4 and the resolution warmed over. Therefore, the mobile phase containing acetonitrile and phosphate buffer at $\mathrm{pH} 3.5(55: 45, \mathrm{v} / \mathrm{v})$ was selected as optimal for obtaining well defined and resolved peaks with mean retention times of $1.7,2.2$ and $6.0 \mathrm{~min}$, for standard solution HCT, AML and VAL, respectively, as shown in Figure 2.

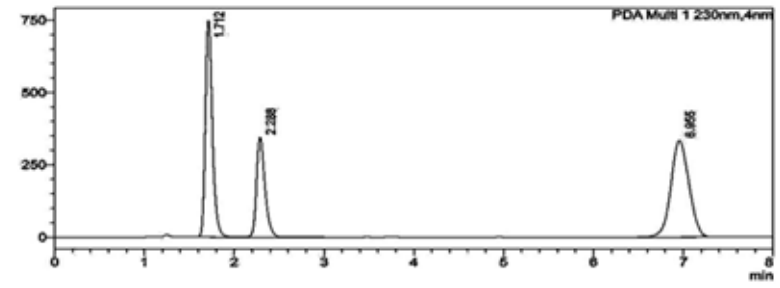

Figure 2 Chromatogram of the standard solutions of HCT, AML and VAL respectively at optimized HPLC conditions.

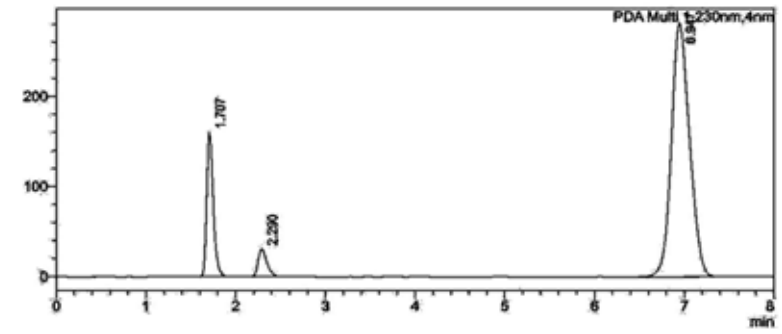

Figure 3 Chromatograms of HCT, AML and VAL respectively in tablets formulation at optimized conditions HPLC.

\section{Validation of the method}

Method validation is the process of determining, through laboratory studies, that the performance characteristics of the method meet the requirements for its intended analytical applications. The characteristics that are studied during method validation include sensitivity, accuracy, precision, specificity, linearity of detector response, range of analyte concentration and robustness.

\section{Specificity}

The specificity of the HPLC method was ascertained by analyzing standard drug and sample solution .The retention time of AML, HCT and VAL were confirmed by comparing the retention time with that of standard.

\section{Linearity}

The linearity of the proposed HPLC procedure was evaluated by analyzing a series of different concentrations for each of the three analytes. The linear regression equations were generated by least squares treatment of the calibration data. Under the optimized conditions described above, the measured peak areas were found to be proportional to concentrations of the analytes. Table 1 presents the performance data and statistical parameters including linear regression equations, concentration ranges, and correlation coefficients. The data obtained from the linearity determination experiments was subjected to linear regression analysis. The linearity equations were y $=23,447.2 \mathrm{x}+3,996.1, \mathrm{R}^{2}=0.9996$ for Amlodipine

$$
y=37,204.5 x+66,638.8, R^{2}=0.9993 \text { for hydrochlorothiazide and }
$$

$y=40,039.99 x+22,825 R^{2}=0.9993$ for valsartan. Correlation coefficient $\mathrm{R}^{2}$ values were in all cases greater than 0.999 indicating a strong correlation between the concentrations of the analytes and the peak areas and therefore the method could be applied in the assay of all or any of the three analyte compounds. A summary of the linearity analysis results obtained is shown in Table 1. The ICH guidelines recommend that for the establishment of linearity a minimum of five concentrations be utilized over the range of 80 to $120 \%{ }^{40,41}$ This method was found to be linear over the range tested for all the three compounds.

\section{Accuracy}

The accuracy of an analytical method is the closeness of the test results obtained by that procedure to a true known value. The accuracy for the developed method was determined by spiking the finished commercial products with working standards of compounds under study. The difference between spiked sample result and the unspiked sample resulted was calculated as percentage of the known added spike concentration. For this purpose one commercial compound that contained all the 3 compounds was used. The standards were added to the samples at 3 concentrations, 50, 100 and $150 \%$ of the assay concentrations and injected in triplicate. The standards were added at amounts that would increase the concentration by $20 \%$. The $\%$ recovery of each added working standard was regarded as the accuracy (Table 2). The recoveries of all compounds were within the specified guidelines (ICH) of $98-103 \%{ }^{33,34}$

\section{Precision}

The precision of an analytical procedure as the closeness of agreement (degree of scatter) between a series of measurements obtained from multiple sampling of the same homogeneous sample under the prescribed conditions. Precision may be considered at three levels: repeatability, intermediate precision and reproducibility. The ICH5 requires repeatability to be tested from at least six replications measured at 100 percent of the test target concentration or from at least nine replications covering the complete specified range.and calculation the relative standard deviation for various assays done on same day or different days. The results obtained are summarized in Table $3 .^{34,35}$ The relative standard deviation in both cases was below $2 \%$ indicating that the method was precise.

\section{Sensitivity}

Limit of detection: The limit of detection (LOD) is the lowest amount of analyte in a sample that can be detected but not necessarily quantified using an analytical technique under specified experimental conditions. The LOD was established by signal over noise $(\mathrm{S} / \mathrm{N})$ method where 6 injection of blank (mobile phase) were injected and the mean peak height was determined. Determination of LOD is indicated for method developed for determination of restricted substances and degradation products that are usually present in small quantities in the sample ${ }^{34}$ while the LOQ was determined for this method to give an idea of the amount of each compound which can be quantified with adequate precision and accuracy to enable the profiling of related substances and degradation products during stability studies. The low limit of detection indicates that the developed method can be used for detection of low concentration of active constituents extracted from samples (Table 1). 
Limit of quantification: The limit of quantification (LOQ) is the lowest amount of analyte in a sample that can be determined with acceptable precision under specified experimental conditions. The degree of precision considered to be acceptable for purposes of LOQ determination from peak areas of six injections, the low limit of quantification indicates that the developed method can be used for quantification of low concentration of active constituents extracted from samples (Table 1).

\section{Robustness}

The robustness of an analytical procedure is a measure of its capacity to remain unaffected by small but deliberate variations in method parameters and provides an indication of its reliability during normal usage..$^{34}$ In liquid chromatography variations of $\mathrm{pH}$ in mobile phase, mobile phase composition, column, temperature and flow rate are considered. Robustness of the method was determined from the degree of variation observed in peak areas and retention times from the same working standard solution analyzed while adjusting each of the liquid chromatographic factors indicated. Six replicate injections of the same working standard solution were run after having adjusted a single chromatographic parameter and coefficient of variation of peak areas of component peaks calculated. The degree of variation observed was then used to infer the method's robustness Table 4.

Table I Parameters of Linearity data for the Amlodipine (AML), Hydrochlorothiazide (HCT), and Valsartan (VAL)

\begin{tabular}{llll}
\hline Parameter & AML & HCT & VAL \\
\hline Measurement wavelength $(\mathrm{nm})$ & 230 & 230 & 230 \\
Linear range $(\mu \mathrm{gg} / \mathrm{mL})$ & $0.2-80$ & $0.2-80$ & $0.25-100$ \\
Standard deviation of the Blank & 74.9 & 74.9 & 74.9 \\
Intercept & $3,996.10$ & 66,639 & $22,824.90$ \\
Slope & $23,447.10$ & $37,204.50$ & 40,040 \\
Correlation coefficient $(\mathrm{r})$ & 0.99996 & 0.9993 & 0.9993 \\
Limit of detection, LOD $(\mu \mathrm{g} / \mathrm{mL})$ & 0.011 & 0.01 & 0.01 \\
Limit of quant., LOQ $(\mu \mathrm{g} / \mathrm{mL})$ & 0.032 & 0.02 & 0.019 \\
\hline
\end{tabular}

Table 2 Recovery studies for the determination of Amlodipine (AML), Hydrochlorothiazide (HCT), and Valsartan (VAL) by the proposed method

\begin{tabular}{|c|c|c|c|c|c|c|}
\hline \multirow[t]{2}{*}{ Sample No } & \multirow[t]{2}{*}{$\begin{array}{l}\text { Sample Content } \\
(\mu \mathrm{g} / \mathrm{mL})\end{array}$} & \multirow[t]{2}{*}{$\begin{array}{l}\text { Average of Amount } \\
\text { Found }(\mu \mathrm{g} / \mathrm{mL})\end{array}$} & \multirow{2}{*}{\multicolumn{3}{|c|}{$\begin{array}{ll}\text { Assay } \% & \begin{array}{l}\text { Recovery } \\
\%\end{array} \\
\text { (Relative to } 100 \% \text { Concentration ) }\end{array}$}} & \multirow[t]{2}{*}{$\begin{array}{l}\text { Average of Recovery } \\
\text { and RSD }\end{array}$} \\
\hline & & & & & & \\
\hline \multicolumn{7}{|l|}{ Amlodipine } \\
\hline \multirow[t]{3}{*}{ AML } & 20 & 19.73 & 49.325 & 98.65 & 0.41 & $99.55 \%$ \\
\hline & 40 & 39.88 & 99.7 & 99.7 & 0.17 & $0.23 \%$ \\
\hline & 60 & 60.18 & 150.45 & 100.3 & 0.12 & \\
\hline \multicolumn{7}{|l|}{$\mathrm{HCT}$} \\
\hline \multirow[t]{3}{*}{$\mathrm{HCT}$} & 20 & 19.74 & 49.35 & 98.7 & 0.21 & $99.52 \%$ \\
\hline & 40 & 39.88 & 99.7 & 99.7 & 0.22 & $0.18 \%$ \\
\hline & 60 & 60.09 & 150.23 & 100.15 & 0.12 & \\
\hline \multicolumn{7}{|l|}{ Valsartan } \\
\hline \multirow[t]{3}{*}{ VAL } & 25 & 24.88 & 49.76 & 99.52 & 0.15 & $100.01 \%$ \\
\hline & 50 & 49.99 & 99.98 & 99.98 & 0.17 & $0.15 \%$ \\
\hline & 75 & 75.41 & 150.82 & 100.55 & 0.13 & \\
\hline
\end{tabular}

Table 3 Influence of small variation in the assay condition on the analytical performance of the Proposed HPLC method for determination of Amlodipine (AML), Hydrochlorothiazide (HCT) and Valsartan (VAL)

\begin{tabular}{|c|c|c|c|c|c|c|c|}
\hline Change In & Before Change & Flow Rate & Flow Rate & Mobile Phase & Mobile Phase & $\lambda \mathbf{n m}$ & $\lambda \mathbf{n m}$ \\
\hline Parameter & & $1.4 \mathrm{ml} / \mathrm{min}$ & $1.6 \mathrm{ml} / \mathrm{min}$ & $+10 \%$ acetonitrile & $-10 \%$ acetonitrile & $-5 n m(225)$ & $+5 \mathrm{~nm}(235)$ \\
\hline \multicolumn{8}{|l|}{ Amlodipine } \\
\hline Retention Time & 2.133 & 2.374 & 2.095 & 2.005 & 3.096 & 2.234 & 2.233 \\
\hline Tailing Factor & 1.277 & 1.288 & 1.272 & 1.276 & 1.288 & 1.275 & $\mathrm{I} .277$ \\
\hline \multicolumn{8}{|c|}{ Hydrochlorothiazide } \\
\hline Retention Time & 1.694 & 1.809 & 1.588 & 1.322 & 1.83 & 2.234 & 1.69 \\
\hline Tailing Factor & 1.222 & 1.247 & 1.244 & 1.212 & 1.234 & 1.223 & 1.244 \\
\hline \multicolumn{8}{|l|}{ Valsartan } \\
\hline Retention Time & 6.332 & 6.939 & 6.129 & 6.122 & 10.526 & 6.534 & 6.521 \\
\hline Tailing Factor & 1.16 & 1.252 & 1.121 & 1.172 & 1.234 & 1.18 & 1.19 \\
\hline
\end{tabular}

Table 4 Precision studies for the determination of Amlodipine (AML), Hydrochlorothiazide (HCT), and Valsartan (VAL) by the proposed method

\begin{tabular}{lllll}
\hline Sample No & \multicolumn{2}{l}{ Intraday Precision } & \multicolumn{2}{l}{ Interday Precision } \\
\hline & Assay \% & RSD \% & Recovery Mean & RSD \% \\
Amlodipine & & & & \\
I & 99.96 & 0.27 & 99.94 & 0.36 \\
2 & 99.4 & 0.23 & 98.1 & 0.32 \\
3 & 99.81 & 0.34 & 99.34 & 0.29 \\
\hline
\end{tabular}


Table Continued...

\begin{tabular}{lllll} 
Sample No & \multicolumn{2}{l}{ Intraday } & Precision & \multicolumn{2}{l}{ Interday Precision } \\
\hline Average & 99.72 & 0.28 & 99.13 & 0.32 \\
All assay & & 99.43 & RSD \% & 0.42 \\
\multicolumn{2}{l}{ Hydrochlorothiazide } & & & \\
I & 98.76 & 0.31 & 98.3 & 0.12 \\
2 & 98.24 & 0.22 & 99.87 & 0.18 \\
3 & 98.55 & 0.27 & 99.23 & 0.31 \\
Average & 98.52 & 0.27 & 99.13 & 0.2 \\
All assay & & 98.83 & RSD \% & 0.44 \\
Valsartan & & & & \\
I & 98.86 & 0.33 & 99.84 & 0.18 \\
2 & 101.76 & 0.24 & 99.05 & 0.13 \\
3 & 99.45 & 0.45 & 99.43 & 0.34 \\
Average & 100.02 & 0.34 & 99.44 & 0.22 \\
All assay & & 99.73 & RSD \% & 0.41 \\
\hline
\end{tabular}

Table 5 Stability studies for the determination of Amlodipine (AML), Hydrochlorothiazide (HCT), and Valsartan (VAL) by the proposed method

\begin{tabular}{|c|c|c|c|c|c|c|}
\hline \multirow[t]{3}{*}{ Time (Month) } & \multicolumn{3}{|c|}{ Accelerated Storage Conditions } & \multicolumn{3}{|c|}{ Real Storage Conditions } \\
\hline & \multicolumn{3}{|c|}{$40^{\circ} \mathrm{C}$ and $75 \%$} & \multicolumn{3}{|c|}{$25^{\circ} \mathrm{C}$ and $60 \%$} \\
\hline & AML \% & HCT \% & VAL \% & AML \% & HCT \% & VAL $\%$ \\
\hline 0Time & 99.72 & 99.13 & 100.02 & 99.72 & 99.13 & 100.02 \\
\hline I month & 99.2 & 100.02 & 98.8 & 101 & 98.6 & 99.47 \\
\hline 2 month & 99.4 & 100.2 & 99.55 & 98.74 & 100.22 & 99.31 \\
\hline 3 month & 99.14 & 99.57 & 99.93 & 98.9 & 99.34 & 99.56 \\
\hline
\end{tabular}

\section{Stability tests}

The stability test results in terms of the average content of AML, HCT, and VAL per tablet, in percentage with respect to the labeled amount, are presented in Table 5. The quantity of AML, HCT, and VAL remained fairly constant in accelerated and real storage until the end of the stability study period (3months). The stability results suggest that No significant degradation was observed and the relative standard deviation between the result of time initial and after 1,2, and 3 months in the stability chamber.

\section{Analysis of pharmaceutical dosage form}

The optimized HPLC procedure was applied for the assay of this drug combination in the pharmaceutical formulation (Exforge HCT tablets). The active ingredients were extracted with the same solvent used for the preparation of the standard stock solutions (HPLC-grade acetonitrile and phosphate buffer 55\%:45\%) then dilution was made with same solvent to reach concentration levels within the specified ranges. The active ingredients eluted at their specific retention times as shown in Figure 3. No interfering peaks were observed from any of the inactive ingredients or the colored coat of the analyzed tablets. The diode-array detection enables peak purity verification where no signs of co-elution from any of the inactive adjutants were detected. Recoveries were calculated using both external standard and standard addition methods. The assay results revealed satisfactory accuracy and precision as indicated from $\%$ recovery, $\mathrm{SD}$ and $\mathrm{RSD} \%$ values Table $2 \& 4$. Although no monograph for the sample combinations are present in official pharmacopoeia, the assay limits specified in the British Pharmacopoeia and United States Pharmacopoeia for single component containing any of the three ingredients were used as a basis for determining whether the products met quality specifications. In all the three cases, the pharmacopoeia specified assay limits of 90$110 \%$ for each drug component ${ }^{3,36}$ (Table 4). It is evident from these results that the proposed method is applicable to the assay of this drug combination with a satisfactory level of selectivity, accuracy and precision.

\section{Discussion}

In this study a method for the simultaneous determination of Amlodipine (AML), hydrochlorothiazide (HCT) and valsartan (VAL) an antihypertensive fixed dose combination in the market was developed. The optimum conditions for the separation of the AML, HCTand VAL was determined using isocratic reversed phase HPLC method by using ODS C-18 $(250 \mathrm{~mm} \times 4.6 \mathrm{~mm}$ i.d. $5 \mu \mathrm{m})$ column because these types of columns are the ones routinely and cheaply used in liquid chromatography analysis of pharmaceuticals. And a mobile phase consisting of acetonitrile- $0.05 \mathrm{M} \mathrm{KH}_{2} \mathrm{PO}_{4} \mathrm{pH} 3.0$ (55:45 $\% \mathrm{v} / \mathrm{v})$. Column temperature was maintained at $40^{\circ} \mathrm{C}$ and the flow rate was $1.5 \mathrm{ml} / \mathrm{min}$. Detection was at $230 \mathrm{~nm}$ and injection of $20 \mu \mathrm{L}$. All components eluting within $6 \mathrm{~min}$. The order of elution of the component was HCT, AML and VAL respectively. The \% recovery was found to be within limits of the acceptance criteria with recovery range 98.6 to $100.3 \%$ for AML, 98.7 to $100.1 \%$ for HCT and 99.5 to $100.5 \%$ for VAL. The high percentage of recovery indicates that the proposed method is highly accurate. The detection limit of the proposed method was $0.011 \mu \mathrm{g} / \mathrm{mL}, 0.10 \mu \mathrm{g} / \mathrm{mL}$ and $0.10 \mu \mathrm{g} / \mathrm{mL}$ and the quantification limit was $0.032 \mu \mathrm{g} / \mathrm{mL}, 0.019 \mu \mathrm{g} / \mathrm{mL}$ and $0.020 \mu \mathrm{g} / \mathrm{mL}$ for AML, VAL and HCT respectively, which indicate the sensitivity of the method. The assay procedures were repeated more times and the results were found to give $99.43 \%, 98.83 \%$ and $99.73 \%$ for AML, HCT and VAL respectively. The number of theoretical plates calculated was 3019, 2404 and 6094 for AML, VAL and HCT respectively, which indicates efficient performance of the column. No interfering peaks were found in the chromatogram of the formulation within the run time indicating that excipients used in tablet formulations did not interfere with the simultaneous estimation of the drugs HCT, VAL and AML by the proposed HPLC method. The study focused on optimization of the conditions for simple, rapid and cost effective analysis including selection of routinely used columns and mobile phases to obtain satisfactory results.

\section{Conclusion}

The present paper described the development of simple, sensitive 
and accurate analytical methods for the simultaneous determination of AML, HCT and VAL in mixtures without the need of prior separation step. The procedure presented here does not need any expensive apparatus; therefore the proposed method can be used advantageously as a routine method for the determination of AML, HCT and VAL in quality control and industry, our method may be applied to the determination the content of the cited drugs in commercial tablets.

\section{Acknowledgements}

None.

\section{Conflicts of interest}

None.

\section{Funding}

None.

\section{References}

1. Calhoun DA, Lacourciere Y, Chiang YT, et al. Triple antihypertensive therapy with amlodipine, valsartan, and Hydrochlorothiazide. Hypertension. 2009;54(1):32-39.

2. Chrysant SG. Single-pill triple-combination therapy: an alternative to multiple-drug treatment of hypertension. Postgrad Med. 2011;123(6):21-31

3. Reynolds JEF. MARTINDALE. The Extra Pharmacopoeia. ( $6^{\text {th }}$ edn $), A$ publication of Pharmaceutical Press, Uk. 2009;1:1214-1420.

4. Nikam MB, Dhamane H, Aligave A, et al. Simultaneous estimation of valsartan, amlodipine besylate and hydrochlorothiazide by first order derivative UV spectrophotometric method. Int $J$ Pharmacy and Technology. 2010;2:642-650.

5. United States Pharmacopoeia United States Pharmacopeial Convention, Twin Brook Parkway, Rockville, USA. 2007. p.2288-3447.

6. British pharmacopoeia 2001. A publication of stationary office Ltd, UK 2001. p.116-860

7. Anandakumar K, Jayamariappan M. Absorption Correction Method For The Simultaeous Estimation of Amlodipine Besylate,Valsartan and Hydrochlorothiazide in Bulk and in Combined Tablet Dosage Form. International Journal of Pharmacy and Pharmaceutical Sciences. 2011;3(1):23-27.

8. Lakshmi KS, Lakshmi S. Simultaneous Spectrophotometric Determination of Valsartan and Hydrochlorothiazide by H-Point Standard Addition Method and Partial Least Squares Regression. Acta Pharmaceutica. 2011;61(1):37-50.

9. Stolarczyk M, Maslanka A, Krzek J, et al. Application of Derivative Spectrophotometry for Determination of Enalapril, Hydrochlorothiazide and Walsartan in Complex Pharmaceutical Preparations. Acta Poloniae Pharmaceutica. 2008;65(3):275-281.

10. Gupta KR, Mahapatra AD, Wadodkar AR, et al. Simultaneous UV Spectrophotometric Determination of Valsartan and Amlodipine in Tablet. International Journal of ChemTech Research. 2010;2(1):551-556.

11. Tatar S, Saglik S. Comparison of UV- and Second DerivativeSpectrophotometric and LC Methods for the Determination of Valsartan in Pharmaceutical Formulation. Journal of Pharmaceutical and Biomedical Analysis. 2002;30(2):371-375.

12. Satana E, Altinay S, Goger NG, et al. Simultaneous Determination of Valsartan and Hydrochlorothiazide in Tablets by First-Derivative Ultraviolet Spectrophotometry and LC. Journal of Pharmaceutical and Biomedical Analysis. 2001;25(5-6):1009-1013.
13. Shaalan R, Belal TS. Simultaneous Spectrofluorimetric Determination of Amlodipine Besylate and Valsartan in Their Combined Tablets, Drug Test Anal. 2010;2(10):489-493.

14. Kul D, Dogan-Topal B, Kutucu T, et al. High-Performance Liquid Chromatographic and First Derivative of the Ratio Spectrophotometric Determination of Amlodipine and Valsartan in Their Binary Mixtures. $J$ AOAC Int . 2010;93(3):882-890.

15. Wei X, Yang G, Qi L, et al. Determination of Nicardipine and Amlodipine in Human Plasma Using On-Line Solid-Phase Extraction with a Monolithic Weak Cation-Exchange Column. Talanta. 2009;77(3):1197-1202.

16. Ramani AV, Sengupta P, Mullangi R. Development and Validation of a Highly Sensitive and Robust LC-ESI-MS/MS Method for Simultaneous Quantitation of Simvastatin Acid, Amlodipine and Valsartan in Human Plasma: Application to a Clinical Pharmacokinetic Study. Biomed Chromatogr. 2009;23(6):615-622.

17. Alsarra IA. High-Performance Liquid Chromatographic Method for Quantitative Determination of Amlodipine in Human Plasma and Pharmaceutical Dosage Form and Its Application to Pharmacokinetic Studies. J Chromatogr Sci . 2009;47(10):863-867.

18. Li H, Wang Y, Jiang Y, et al. A liquid Chromatography/Tandem Mass Spec-trometry Method for the Simultaneous Quantification of Valsartan and Hydrochlorothiazide in Human Plasma. Journal of Chromatography B. 2007;852(1-2):436-442.

19. Iriarte G, Ferreiros N, Ibarrondo I, et al. Optimization via Experimental Design of an SPE-HPLC-UV-Fluo-rescence Method for the Determination of Valsartan and Its Metabolite in Human Plasma Samples. J Sep Sci . 2006;29(15):2265-2283.

20. Tian DF, Tian XL, Tian T, et al. Simultaneous Determination of Valsartan and Hydro-chlorothiazide in Tablets by RP-HPLC. Indian J Pharm Sci. 2008;70(3):372-374.

21. Chitlange SS, Bagri K, Sakarkar DM. Stability Indicating RP-HPLC Method for Simultaneous Estimation of Valsartan and Amlodipine in Capsule Formulation. Asian Journal of Research in Chemistry. 2014;13(1):809-817.

22. Iriarte G, Gonzalez O, Ferreiros N, et al. Validation of a Fast Liquid Chromatography-UV Method for the Analysis of Drugs Used in Combined Cardiovascular Therapy in Human Plasma. J Chromatogr B Analyt Technol Biomed Life Sci . 2009;877(27):3045-3053.

23. Shah NJ, Suhagia BN, Shah RR, et al. HPTLC Method for the Simultaneous Estimation of Valsartan and Hydrochlorothiazide in Tablet Dosage Form. Indian J Pharm Sci. 2009;71(1):72-74.

24. Varghese SJ, Ravi TK. Quantitative Simultaneous Determination of Amlodipine, Valsartan, and Hydrochlorothiazide in 'Exforge HCT' Tablets Using High-Performance Liquid Chromatograhy and High-Performance Thin-Layer Chromatography. Journal of Liquid Chromatography \& Related Technologies. 2011;34(12):981-994.

25. Argekar A, Powar S. Simultaneous determination of atenolol and amlodipine in tablets by high performance thin-layer chromatography. J Pharm Biomed Anal . 2000;21(6):1137-1142.

26. Alnajjar AO. Validation of a Capillary Electrophoresis Method for the Simultaneous Determination of Amlodipine Besylate and Valsartan in Pharmaceuticals and Human Plasma. J AOAC Int. 2011;94(2):498-502.

27. Hillaert S, Van den Bossche W. Simultaneous Determination of Hydrochlorothiazide and Several Angio-tensin-II-Receptor Antagonists by Capillary Electrophoresis. Journal of Pharmaceutical and Biomedical Analysis. 2003;31(2):329-339.

28. Hillaert S, Van den Bossche W. Optimization and Validation of a Capillary Zone Electrophoretic Method for the Analysis of Several Angiotensin-II-Receptor An-tagonist. Journal of Chromatography A. 2002;979(1-2):323-333. 
29. Gonzalez L, Akesolo U, Jimenez RM, et al. Application of Capillary Zone Electrophoresis to the Screening of Some Angiotensin II Receptor An-tagonists. Electrophoresis . 2002;23(2):223-229.

30. Yan J, Wang W, Chen L, et al. Electrochemical Behavior of Valsartan and Its Determination in Capsules. Colloids Surf B Biointerfaces . 2008;67(2):205-209.

31. Gazy AA. Determination of Amlodipine Besylate by Adsorptive SquareWave Anodic Stripping Voltammetry on Glassy Carbon Electrode in Tablets and Biological Fluid. Talanta. 2004;62(3):575-582.

32. Altiokka G, Dogrukol-Ak D, Tuncel M, et al. Determination of Amlodipine in Pharmaceutical Formulations by Differential Pulse Voltammetry with a Glassy Carbon Electrode. Arch Pharm (Weinheim). 2002;335(2):104-108.
33. ICH. Stability testing of new drug substances and products. International Conference on Harmonization of Technical Requirements for Registration of Pharmaceuticals for Human Use. 2003.

34. The United States Pharmacopoeia 31 National Formulary 26 (U.S.P. 31 N.F. 26). United States Pharmacopoeial Convention Inc. Rockville, USA. 2008.

35. www.scribd.com/doc/.../ICH-Validation-of-Analytical-Procedures

36. ICH. Validation of analytical procedures: text and methodology. International Conference on Harmonization of Technical Requirements for Registration of Pharmaceuticals for Human Use: ICH Triplicate Guidelines. 2005. 